\title{
Optimizing the adhesion of soil-touching parts based on biomimetic concepts using the Taguchi method
}

\author{
Abouelnadar El. Salem ${ }^{1,2}$, Guozhong Zhang ${ }^{1,3^{*}}$, Mohamed Anwer Mahmoud Abdeen ${ }^{1,4}$, \\ Hongchang Wang ${ }^{1}$, Yuan $\mathrm{GaO}^{1}$ \\ (1. College of Engineering, Huazhong Agricultural University, Wuhan 430070, China; \\ 2. Soil Conservation Department, Desert Research Center, Cairo 11753, Egypt; \\ 3. Modern Agricultural Equipment Engineering Technology Research Center, Wuhan 430070, China; \\ 4. Agricultural Engineering Department, College of Agriculture, Zagazig University, Zagazig 44519, Egypt)
}

\begin{abstract}
Several studies highlighted that the surface shape modifications which are inspired by the soil-burrowing animals have positively impacted the soil-tool adhesion; however, it is still unclear what the optimum dimensions of the domed surface are for minimizing soil-tool adhesion. In this study, twenty-seven domed discs were created according to Taguchi orthogonal array $\mathrm{L} 27\left(3^{3}\right)$ to determine the optimum dimensions of the domed surface that minimize normal adhesion force and disc sinkage simultaneously, as well as comparing the effect of the optimized domed disc versus the flat disc on the normal adhesion force under different soil conditions. The results revealed that disc coverage ratio and dome height to diameter ratio are essential to design parameters that influence the normal adhesion force of discs. According to the signal-to-noise ratio analysis, it was observed that the combination of $60 \%$ disc coverage ratio, $25 \%$ dome height to diameter ratio, and $10 \mathrm{~mm}$ dome base diameter was found to be the most appropriate for the well-balanced improvement of both normal adhesion force and disc sinkage simultaneously. In all treatments, the optimized domed disc produced less normal adhesion force than the flat disc (about $7 \%-18 \%$, according to soil condition). It can be concluded that properly designed domed surfaces can significantly reduce the normal adhesion force when compared to flat surfaces.
\end{abstract}

Keywords: biomimetics, paddy soil, normal adhesion, disc sinkage, Taguchi method

DOI: $10.25165 /$ j.ijabe.20221501.6147

Citation: Salem A E, Zhang G Z, Abdeen M A M, Wang H C, Gao Y. Optimizing the adhesion of soil-touching parts based on biomimetic concepts using the Taguchi method. Int J Agric \& Biol Eng, 2022; 15(1): 147-154.

\section{Introduction}

Farmers and agronomists are always looking for ways to improve the efficiency of their agricultural operations. Agricultural systems generate and consume energy; therefore, the desired agricultural activity must reduce energy consumption ${ }^{[1,2]}$. During the rice-planting season, the moisture content of the paddy soil reaches a relatively high value, which explains why the paddy soils have a significant adhesion force and exceptional rheological properties $^{[3-5]}$. The rheological properties of the soil, particularly the vertical stress-strain relationship, are critical for understanding the soil-tool interaction ${ }^{[6]}$.

Force requirements of agricultural operations (draft forces and normal forces) are related to the machine geometry, soil characteristics, and operating parameters ${ }^{[7]}$. Estimating the force requirements for agricultural machinery operation while taking

\section{Received date: 2020-09-07 Accepted date: 2021-07-05}

Biographies: Abouelnadar El. Salem, PhD candidate, research interest: soil adhesion and agricultural machinery, Email: abouelnadar@webmail.hzau.edu.cn; Mohamed Anwer Mahmoud Abdeen, $\mathrm{PhD}$ candidate, research interest: agricultural machinery, Email: mohamed.anwer2010@yahoo.com; Hongchang Wang, $\mathrm{PhD}$, research interest: agricultural machinery, Email: wanghc84@mail.hzau.edu.cn; Yuan Gao, MS candidate, research interest: soil adhesion and agricultural machinery, Email: gaoyuan@mail.hzau.edu.cn.

*Corresponding author: Guozhong Zhang, $\mathrm{PhD}$, Professor, research interest: agricultural machinery. Huazhong Agricultural University, Wuhan 430070, China. Tel: +86-18672783365, Email: zhanggz@mail.hzau.edu.cn. different soil conditions into account is therefore critical for optimizing tool design ${ }^{[8]}$. Internal friction, cohesion, and adhesion are the three most important soil characteristics in determining the operating requirements of agricultural machinery. The term of soil adhesion refers to the force of attraction between soil particles and the surface contacting the soil caused by surface tension and viscosity of the thin interfacial water film ${ }^{[9]}$. Based on various theories previously proposed ${ }^{[10]}$, classified the adhesion forces at soil-tool interface into tangential adhesion force and normal adhesion force. The soil-tool adhesion had caused a significant negative impact on the germination rate ${ }^{[11]}$, increased energy consumption of tillage equipment by $30 \%-50 \%{ }^{[12]}$, decreased the efficiency of the working components ${ }^{[13]}$, and reduced the working productivity of loading and excavating machines by approximately $30 \%{ }^{[14]}$

Over the last decades, researchers have focused on improving the performance of soil-engaging components in order to increase the efficiency of agricultural operations while reducing energy consumption. They mentioned that several methodologies had significantly reduced soil-tool adhesion, such as modifying the surface geometry of soil-touching components ${ }^{[15,16]}$, coating the surface of soil-touching components with polymeric materials ${ }^{[7,17]}$, employing mechanical and ultrasonic vibration ${ }^{[18]}$, utilizing electro-osmotic phenomenon ${ }^{[19]}$, and lubricating the surface of soil-touching components with liquid substances ${ }^{[9]}$.

Since the late twentieth century, surface shape modification has been widely recognized and documented as one of the most 
effective methods among the aforementioned approaches. Many factors influence soil adhesion to domed bulldozer blades ${ }^{[20]}$, including dome density, dome base diameter, dome distribution pattern, and dome height. Attaching ultra-high molecular weight polyethylene (UHMW-PE) domes to a mouldboard plough reduced ploughing resistance in sticky soil by $18 \%$ to $36 \%$, depending on operating conditions and dome dimensions ${ }^{[15]}$. The impact of installing concave and convex units to a disc plough was studied by Benard et al. ${ }^{[21]}$, and they concluded that the convex units $(3 \mathrm{~mm}$ in height, a coverage ratio of $30 \%$, and a base diameter of $20 \mathrm{~mm}$ ) were more effective in reducing ploughing resistance by $19 \%$ at a forward speed of $4.4 \mathrm{~km} / \mathrm{h}$.

Soil adhesion to machine parts is a major issue, particularly in moist and sticky soils Figure 1. Soni and Salokhe ${ }^{[22]}$ concluded that properly designed domed surfaces can reduce the soil-tool adhesion; however, determining the optimal dimensions of the domed surface require far more attention. As a result, additional experimental studies in this area are required. The purpose of this paper was to look at the impacts of specific geometric dimensions of domed surfaces (disc coverage ratio, dome height-to-diameter ratio, and dome base diameter) on normal adhesion force and disc sinkage. Moreover, the normal adhesion force of the optimized domed disc was compared to that of the flat disc under various soil conditions.

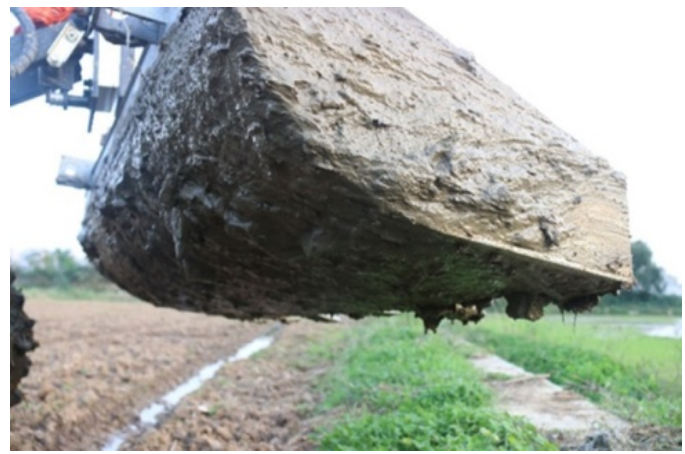

Figure 1 Soil-tool adhesion in paddy fields

\section{Materials and methods}

The laboratory experiments were conducted in the soil mechanic laboratories of Huazhong Agricultural University. Disc coverage ratio (CR) (i.e., the ratio of the base area occupied by the domes to the total area of test disc), dome height to diameter ratio (HDR) and dome base diameter (DBD) were selected as control parameters, each with three levels. Table 1 shows the levels of control parameters that were chosen based on the findings of previous studies on the effect of surface shape modifications on soil-tool adhesion $^{[21-23]}$.

Table 1 Selected values of control parameter levels

\begin{tabular}{lcccc}
\hline \multirow{2}{*}{ Parameters } & Symbol & \multicolumn{3}{c}{ Level } \\
\cline { 3 - 5 } & & 1 & 2 & 3 \\
\hline Disc Coverage ratio CR/\% & $\mathrm{A}$ & 45 & 60 & 75 \\
Dome height to diameter ratio HDR/\% & $\mathrm{B}$ & 12.5 & 25.0 & 37.5 \\
Dome base diameter DBD/mm & $\mathrm{C}$ & 10 & 20 & 30 \\
\hline
\end{tabular}

\subsection{Soil preparation}

A fertile top layer of soil $(0-30 \mathrm{~cm})$ was collected independently from two different sites in Hubei Province, China: a paddy field at Huazhong Agricultural University $\left(30^{\circ} 28^{\prime} 26^{\prime \prime} \mathrm{N}\right.$, $\left.114^{\circ} 20^{\prime} 49^{\prime \prime} \mathrm{E}\right)$ and a wheat field in Jingmen $\left(30^{\circ} 52^{\prime} 18^{\prime \prime} \mathrm{N}\right.$, $\left.112^{\circ} 10^{\prime} 14^{\prime \prime} \mathrm{E}\right)$. Soil samples were air-dried for about two weeks before being hammered and passed through a $2 \mathrm{~mm}$ mesh sieve, as shown in Figure 2. The amount of water needed to achieve the desired soil moisture content was calculated and added to the sieved soil. The soil paste was remolded into a soil-bin of $25 \mathrm{~cm} \times$ $35 \mathrm{~cm} \times 25 \mathrm{~cm}$ (height $\times$ length $\times$ width). The upper plastic limit (liquid limit, LL) and lower plastic limit (plastic limit, PL) were measured in the soil physics laboratories of Huazhong Agricultural University according to ASTM D 4318 standard $^{[24]}$, and the results are listed in Table 2.

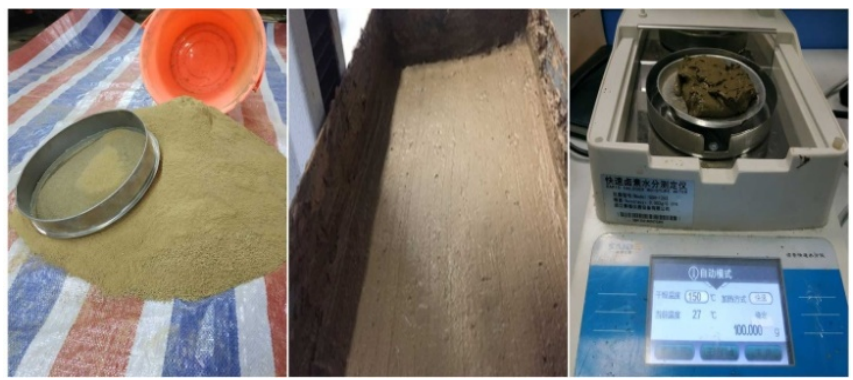

Figure 2 Preparation of experimental soil for normal adhesion force tests

Table 2 Experimental soil characteristics

\begin{tabular}{|c|c|c|c|c|c|c|c|}
\hline \multirow{2}{*}{ Field crop } & \multirow{2}{*}{ Soil texture } & \multirow{2}{*}{ Symbol } & \multicolumn{3}{|c|}{ Soil Particle size distribution $/ \%$} & \multicolumn{2}{|c|}{ Consistency limits/\% } \\
\hline & & & Sand $(>50 \mu \mathrm{m})$ & Silt $(2-50 \mu \mathrm{m})$ & Clay $(<2 \mu \mathrm{m})$ & Liquid limit & Plastic limit \\
\hline Paddy & Silt loam & $\mathrm{S} 1$ & 21.65 & 62.68 & 15.67 & 42 & 20 \\
\hline Wheat & Sandy clay loam & $\mathrm{S} 2$ & 70.11 & 2.72 & 27.17 & 34 & 18 \\
\hline
\end{tabular}

\subsection{Design of experiments}

The present study was conducted in two distinct stages; the first one aimed to determine the optimal levels of the aforementioned control parameters to minimize normal adhesion force and disc sinkage simultaneously. For this purpose, L27 $\left(3^{3}\right)$ Taguchi standard orthogonal array was adopted. At this stage, the silt loam soil (S1) with a moisture content of $37 \mathrm{~g} / 100 \mathrm{~g}$ was used. The second stage involved comparing the effect of the optimized domed disc (identified in the first stage) versus the flat disc on normal adhesion force under two different soil textures (silt loam and sandy clay loam). Each soil texture was tested at three different soil moisture content levels $(23 \%, 30 \%$, and $37 \%$ dry-based). The geometrical dimensions of the dome were calculated using the equations listed below:

The oblate spheroid (dome) has a surface area $(\mathrm{Sa})$ and volume ( $V$ ) defined as

$$
\begin{gathered}
\mathrm{Sa}=\frac{1}{2}\left[2 \pi b^{2}\left(1+\frac{\left(1-e^{2}\right) * \tanh ^{-1} e}{e}\right)\right] \\
V=\frac{2 \pi b^{2} c}{3}
\end{gathered}
$$

where, $e^{2}=1-\left(c^{2} / b^{2}\right) ; b$ is the dome base radius, $\mathrm{mm} ; c$ is the dome height, $\mathrm{mm}$.

Table 3 lists the geometrical details of various combinations of control parameter levels. 
Table 3 Geometrical specifications of test discs

\begin{tabular}{|c|c|c|c|c|c|c|c|c|}
\hline Disc No. & $\mathrm{CR} / \%$ & $n$ & $\mathrm{~b} / \mathrm{mm}$ & $c / \mathrm{mm}$ & $L / \mathrm{mm}$ & $\mathrm{Sa} / \mathrm{mm}^{2}$ & $V / \mathrm{mm}^{3}$ & $V_{t} / \mathrm{mm}^{3}$ \\
\hline 1 & 45 & $\approx 45$ & 5 & 1.25 & 13.0 & 89 & 65 & 2925 \\
\hline 2 & 45 & $\approx 11$ & 10 & 2.50 & 26.0 & 356 & 524 & 5764 \\
\hline 3 & 45 & $\approx 5$ & 15 & 3.75 & 39.0 & 801 & 1767 & 8835 \\
\hline 4 & 45 & $\approx 45$ & 5 & 2.50 & 13.0 & 108 & 131 & 5895 \\
\hline 5 & 45 & $\approx 11$ & 10 & 5.00 & 26.0 & 434 & 1047 & 11517 \\
\hline 6 & 45 & $\approx 5$ & 15 & 7.50 & 39.0 & 976 & 3534 & 17670 \\
\hline 7 & 45 & $\approx 45$ & 5 & 3.75 & 13.0 & 132 & 196 & 8820 \\
\hline 9 & 45 & $\approx 5$ & 15 & 11.25 & 39.0 & 1185 & 5301 & 26505 \\
\hline 10 & 60 & $\approx 60$ & 5 & 1.25 & 11.5 & 89 & 65 & 3900 \\
\hline 11 & 60 & $\approx 15$ & 10 & 2.50 & 23.0 & 356 & 524 & 7860 \\
\hline 12 & 60 & $\approx 7$ & 15 & 3.75 & 34.5 & 801 & 1767 & 12369 \\
\hline 13 & 60 & $\approx 60$ & 5 & 2.50 & 11.5 & 108 & 131 & 7860 \\
\hline 14 & 60 & $\approx 15$ & 10 & 5.00 & 23.0 & 434 & 1047 & 15705 \\
\hline 15 & 60 & $\approx 7$ & 15 & 7.50 & 34.5 & 976 & 3534 & 24738 \\
\hline 16 & 60 & $\approx 60$ & 5 & 3.75 & 11.5 & 132 & 196 & 11760 \\
\hline 18 & 60 & $\approx 7$ & 15 & 11.25 & 34.5 & 1185 & 5301 & 37107 \\
\hline 19 & 75 & $\approx 75$ & 5 & 1.25 & 10.2 & 89 & 65 & 4875 \\
\hline 20 & 75 & $\approx 19$ & 10 & 2.50 & 20.4 & 356 & 524 & 9956 \\
\hline 21 & 75 & $\approx 8$ & 15 & 3.75 & 30.6 & 801 & 1767 & 14136 \\
\hline 22 & 75 & $\approx 75$ & 5 & 2.50 & 10.2 & 108 & 131 & 9825 \\
\hline 23 & 75 & $\approx 19$ & 10 & 5.00 & 20.4 & 434 & 1047 & 19893 \\
\hline 24 & 75 & $\approx 8$ & 15 & 7.50 & 30.6 & 976 & 3534 & 28272 \\
\hline 25 & 75 & $\approx 75$ & 5 & 3.75 & 10.2 & 132 & 196 & 14700 \\
\hline 26 & 75 & $\approx 19$ & 10 & 7.50 & 20.4 & 526 & 1571 & 29849 \\
\hline 27 & 75 & $\approx 8$ & 15 & 11.25 & 30.6 & 1185 & 5301 & 42408 \\
\hline
\end{tabular}

Note: CR: Coverage ratio of the disc; $n$ : Number of the domes required to meet a coverage ratio of that disc; $b$ : Dome base radius; $c$ : dome height; $L$ : Dome to dome an row to row spacing; Sa: Surface area of the oblate spheroid dome, $V$ : Volume of the oblate spheroid dome, $V_{t}$ : Total volume of domes of that disc $\left(V_{t}=n \cdot V\right)$.

\subsection{Preparation of the biomimetic discs}

The structure diagram of a test disc is shown in Figure 3. According to Taguchi design $\mathrm{L} 27\left(3^{3}\right)$, Twenty-seven domed circular discs of $100 \mathrm{~mm}$ in diameter $\left(78.54 \mathrm{~cm}^{2}\right.$ in area) were created, as shown in Figure 4. The design of discs was inspired by the micro-convex structure of the dung beetle head (as shown in Figure 5). The discs were made of Acrylonitrile butadiene styrene (ABS), a material commonly used in 3D printing technology. Discs were equipped with hexagonal bolts for easy fastening and unfastening. Circular nuts were also added to ensure that the bolt's axis would remain perpendicular to the soil-tool interface.

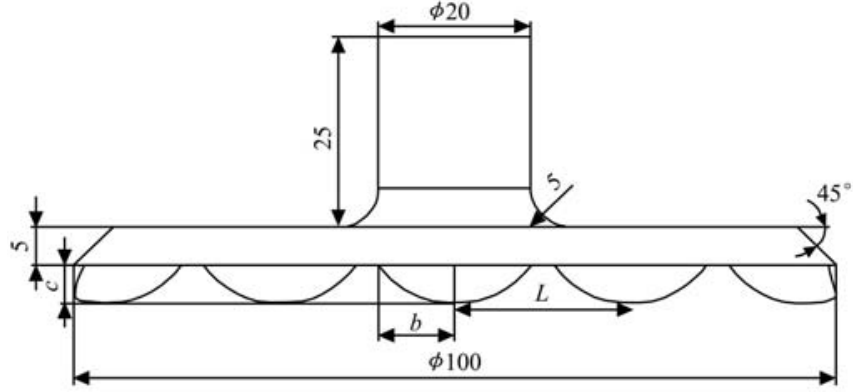

Figure 3 Structure diagram of the disc (mm)
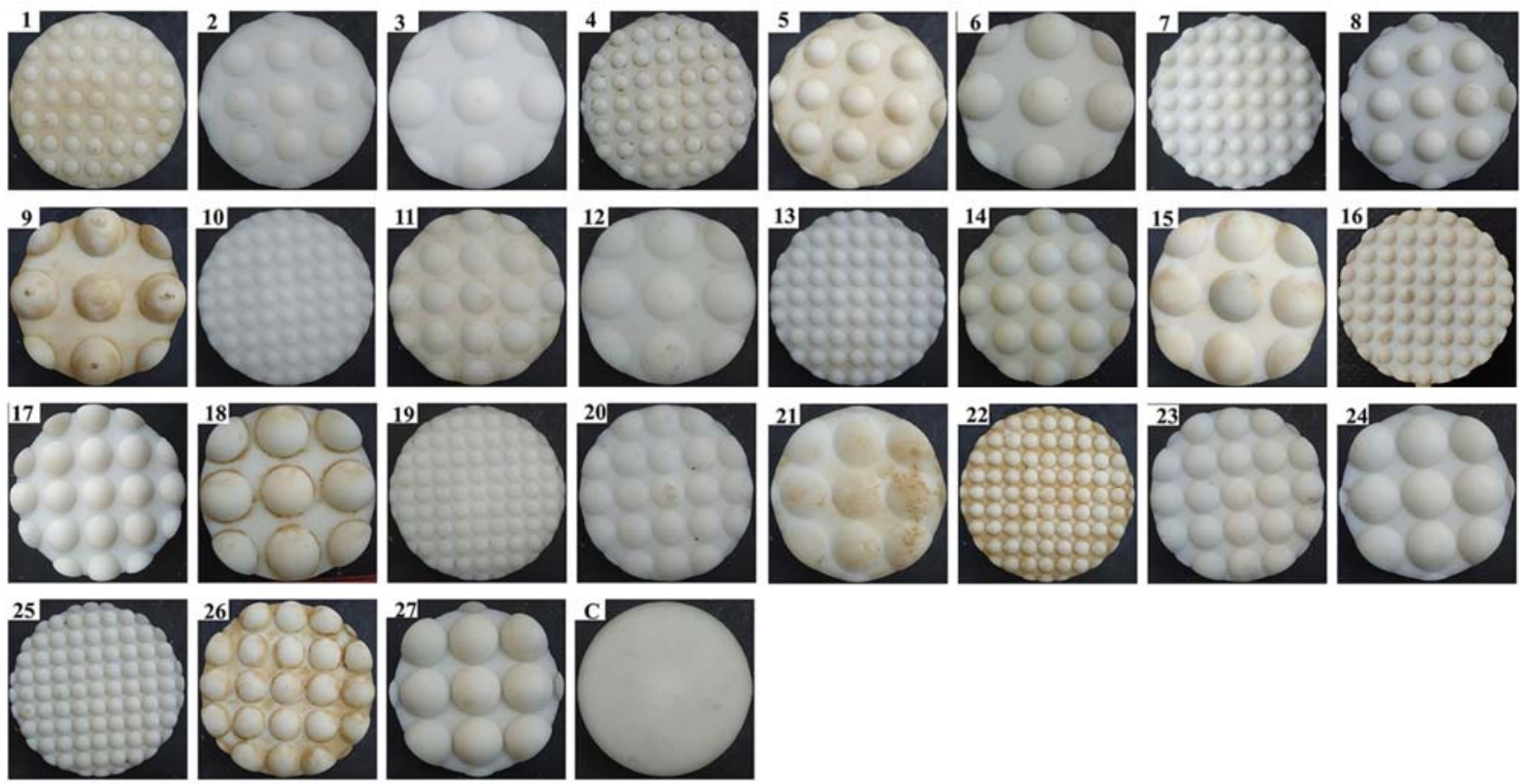

Figure 4 Different combinations of control parameter levels according to the experimental design of Taguchi orthogonal array L27 $\left(3^{3}\right)$ and the control 


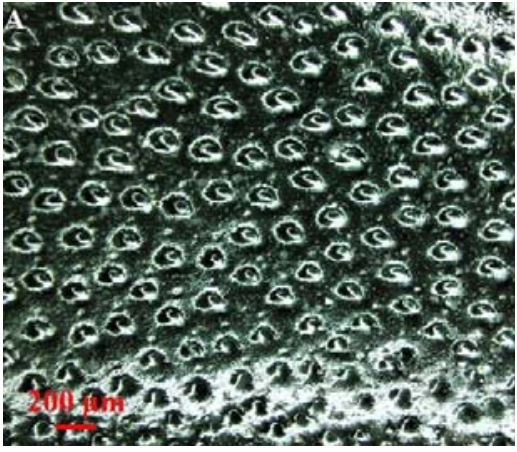

Figure 5 Enlarged image of the dung beetle head as biomimetic structural element ${ }^{[22]}$

\subsection{Normal adhesion force and disc sinkage measurements}

For the tests, a TMS-PRO texture analyzer (food technology corporation of the United States) with a $1000 \mathrm{~N}$ load cell, $0.1 \mathrm{~N}$ accuracy, and a speed range of 0.1-500.0 $\mathrm{mm} / \mathrm{min}$ was used, as shown in Figure 6. On each trial, the test disc was pressed normally into the soil at a constant speed of $10 \mathrm{~mm} / \mathrm{min}$ until the soil penetration resistance reached $40 \mathrm{~N}$, as shown in Figure 7a, and the sinkage of each test disc (from the soil surface till the soil penetration resistance reached $40 \mathrm{~N}$ ) was measured. Following $60 \mathrm{~s}$ of stability, the test disc was lifted at a constant speed of $500 \mathrm{~mm} / \mathrm{min}$, and the maximum force required to separate the disc was measured, as shown in Figure $7 \mathrm{~b}$. Each trial was replicated three times.
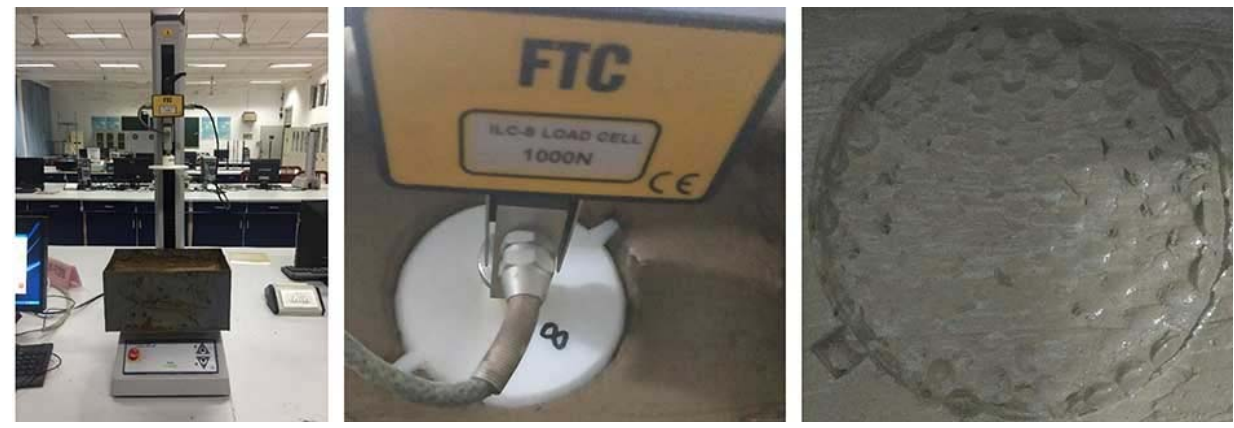

Figure 6 Measurement of the normal adhesion force and disc sinkage using a TMS-PRO texture analyzer

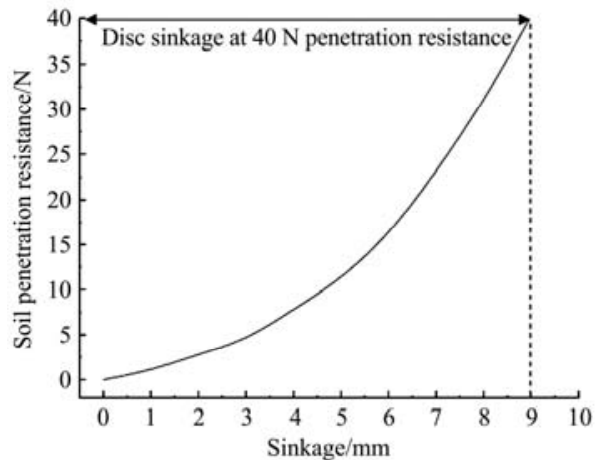

a. Disc sinkage for disc No. $19(\mathrm{U}=8.97 \mathrm{~mm})$

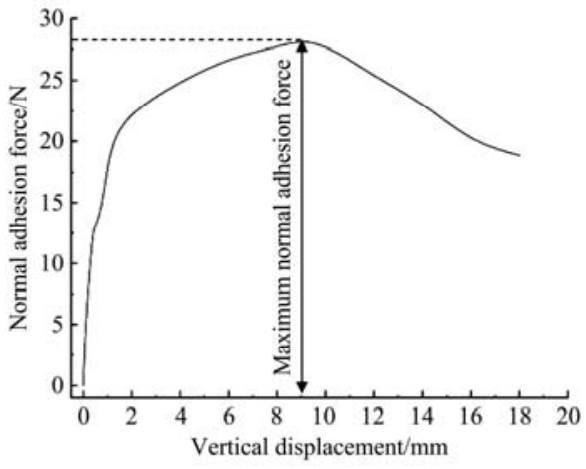

b. Normal adhesion force for disc No. $5(F a=28.6 \mathrm{~N})$

Figure 7 Process of measuring disc sinkage and normal adhesion force

\subsection{Statistical analysis}

In this experiment, the Taguchi method is used to determine the optimal levels of control parameters that minimize normal adhesion force and disc sinkage. According to Genichi Taguchi, the $(\mathrm{S} / \mathrm{N})$ ratio can be used as a statistical indicator of a quantitative analysis tool to determine the optimum levels of control parameters ${ }^{[25]}$. The $\mathrm{S} / \mathrm{N}$ ratio for the "lower is better" approach was adopted and calculated using Equation (3) because the lower the normal adhesion force and disc sinkage values, the better ${ }^{[26]}$.

$$
S / N=-10 \log \left[\frac{1}{n} \sum_{i=1}^{n} y_{i}^{2}\right]
$$

where, $n$ is the number of all trials; $y_{i}$ is the measured data of the trial number $i$-th.

The contributions ratio of disc coverage ratio (A), dome height to diameter ratio (B), and dome base diameter (C) on normal adhesion force and disc sinkage was determined using analysis of variance (ANOVA) with a 5\% significance level. The results were analyzed using Minitab software. Paired samples $t$-test was used to validate the significance of the differences between the optimized domed disc and the flat disc under different soil conditions. Equation (4) was used to calculate the improvement ratio:

$$
\mathrm{IMPV}=\frac{\mathrm{Fa}_{F}-\mathrm{Fa}_{B}}{\mathrm{Fa}_{F}} \times 100 \%
$$

where, IMPV is the percentage of improvement in normal adhesion force; $\mathrm{Fa}_{F}$ and $\mathrm{Fa}_{B}$ are the mean normal adhesion force of the flat disc and the optimum domed disc, respectively.

\section{Results and discussion}

Table 4 displays the measured values of normal adhesion force and disc sinkage for all possible combinations of control parameter levels. The minimum normal adhesion force $(28.6 \mathrm{~N})$ was obtained with a disc coverage ratio of $45.0 \%$, a dome height to diameter ratio of $25.0 \%$, and a dome base diameter of $20 \mathrm{~mm}$ (Disc No. 5), whereas the minimum sinkage of the test discs $(8.32 \mathrm{~mm})$ was obtained with a disc coverage ratio of $75.0 \%$, a dome height to diameter ratio of $12.5 \%$, and a dome base diameter of $10 \mathrm{~mm}$ (Disc No. 19). It was observed that disc number 13, i.e., with a disc coverage ratio of $60 \%$, dome height to diameter ratio of $25 \%$ and dome base diameter of $10 \mathrm{~mm}$, was the most appropriate for the well-balanced improvement of normal adhesion force $(31.4 \mathrm{~N})$ and sinkage $(9.08 \mathrm{~mm})$ simultaneously. 
Table 4 Measured values of normal adhesion force and disc sinkage and $\mathrm{S} / \mathrm{N}$ ratios calculated values

\begin{tabular}{|c|c|c|c|c|c|c|}
\hline $\begin{array}{l}\text { Disc } \\
\text { No. }\end{array}$ & $\mathrm{Fa} / \mathrm{N}$ & $\begin{array}{c}\mathrm{S} / \mathrm{N} \text { ratio } \\
\text { for } \mathrm{Fa}\end{array}$ & Control & $\Delta / \%$ & $U / \mathrm{mm}$ & $\begin{array}{l}\mathrm{S} / \mathrm{N} \text { ratio } \\
\quad \text { for } U\end{array}$ \\
\hline 1 & 35.4 & -31.0 & 37.3 & -5.1 & 10.34 & -20.3 \\
\hline 2 & 34.6 & -30.8 & 37.3 & -7.2 & 12.50 & -21.9 \\
\hline 3 & 36.1 & -31.2 & 37.3 & -3.2 & 13.61 & -22.7 \\
\hline 4 & 29.8 & -29.5 & 37.3 & -20.1 & 10.59 & -20.5 \\
\hline 5 & 28.6 & -29.1 & 37.3 & -23.3 & 11.66 & -21.3 \\
\hline 6 & 32.0 & -30.1 & 37.3 & -14.2 & 14.37 & -23.1 \\
\hline 7 & 35.2 & -30.9 & 37.3 & -5.6 & 13.61 & -22.8 \\
\hline 8 & 34.4 & -30.7 & 37.3 & -7.8 & 14.12 & -23.0 \\
\hline 9 & 37.8 & -31.5 & 37.3 & 1.3 & 15.17 & -23.6 \\
\hline 10 & 38.1 & -31.6 & 37.3 & 2.1 & 9.98 & -20.0 \\
\hline 11 & 38.3 & -31.7 & 37.3 & 2.7 & 10.72 & -20.6 \\
\hline 12 & 37.3 & -31.4 & 37.3 & 0 & 12.48 & -21.9 \\
\hline 13 & 31.4 & -29.9 & 37.3 & -15.8 & 9.08 & -19.2 \\
\hline 14 & 34.7 & -30.8 & 37.3 & -6.9 & 11.72 & -21.4 \\
\hline 15 & 33.6 & -30.5 & 37.3 & -9.9 & 12.60 & -22.0 \\
\hline 16 & 36.4 & -31.2 & 37.3 & -2.4 & 11.20 & -21.0 \\
\hline 17 & 36.2 & -31.2 & 37.3 & -2.9 & 14.37 & -23.1 \\
\hline 18 & 35.4 & -31.0 & 37.3 & -5.1 & 14.88 & -23.5 \\
\hline 19 & 39.7 & -32.0 & 37.3 & 6.4 & 8.32 & -18.4 \\
\hline 20 & 37.3 & -31.4 & 37.3 & 0 & 9.45 & -19.5 \\
\hline 21 & 39.9 & -32.0 & 37.3 & 6.9 & 10.80 & -20.7 \\
\hline 22 & 36.1 & -31.6 & 37.3 & -3.2 & 8.59 & -18.7 \\
\hline 23 & 34.1 & -30.7 & 37.3 & -8.5 & 10.97 & -20.8 \\
\hline 24 & 35.7 & -31.1 & 37.3 & -4.2 & 12.11 & -21.7 \\
\hline 25 & 38.9 & -31.8 & 37.3 & 4.3 & 9.83 & -19.9 \\
\hline 26 & 37.0 & -31.4 & 37.3 & -0.1 & 13.01 & -22.3 \\
\hline 27 & 40.1 & -32.1 & 37.3 & 7.5 & 12.86 & -22.2 \\
\hline
\end{tabular}

Note: $\mathrm{Fa}$ is the normal adhesion force of test discs; $\mathrm{S} / \mathrm{N}$ is the signal to noise ratio response values; $U$ is the subsidence of test discs; $\Delta$ refers to changes in the normal adhesion force of biomimetic disc with respect to flat disc in the same soil conditions, the negative values of $\Delta$ indicate an improvement.

\subsection{Analysis of the signal-to-noise $(\mathrm{S} / \mathrm{N})$ ratio}

The signal-to-noise ratio response values for each level of the control parameters are displayed graphically in Figure 8 . The best level for each control parameter was defined by the highest $\mathrm{S} / \mathrm{N}$ ratio among the levels of that parameter.

According to Figure 8a, the combination of control parameter levels resulting in the minimum normal adhesion force was A1B2C2, i.e., disc coverage ratio (level $1, \mathrm{~S} / \mathrm{N}=-30.54$ ), dome height to diameter ratio (level $2, \mathrm{~S} / \mathrm{N}=-30.32$ ), and dome base diameter (level 2, $\mathrm{S} / \mathrm{N}=-30.86$ ) based on factor level and $\mathrm{S} / \mathrm{N}$ ratio. The lowest disc coverage ratio (45\%) produced the highest $\mathrm{S} / \mathrm{N}$ ratio $(-30.54)$, indicating that the normal adhesion force increased as the coverage ratio increased above 45 percent. These findings support the biomimetic theory, as the dung beetle head has the same coverage ratio (about $45 \%)^{[21]}$. Similarly, the combination of control parameter levels giving the minimum disc sinkage was identified as $\mathrm{A} 3 \mathrm{~B} 1 \mathrm{C} 1$ i.e., disc coverage ratio (level 3, $\mathrm{S} / \mathrm{N}=$ -20.39), dome height to diameter ratio (level $1, \mathrm{~S} / \mathrm{N}=-20.45$ ), and dome base diameter (level 1, $\mathrm{S} / \mathrm{N}=-19.91$ ). The differences in disc sinkage may be due to differences in dome convexity, which affects the disc's ability to penetrate the soil. From the above, we may deduce that the degree of dome oblateness (HDR) and the disc coverage ratio are important factors that affect the normal adhesion force and sinkage of test discs.

\subsection{ANOVA Analysis}

ANOVA is a statistical technique for determining the individual contributions of each control parameter in an experimental design. ANOVA was used in this study at a $95 \%$ confidence level to determine the effect of the aforementioned control parameters on normal adhesion force and disc sinkage. Table 5 lists the ANOVA results. It can be seen that the dome height to diameter ratio had the greatest influence $(50.2 \%)$ on the normal adhesion force of domed discs. As such, the dome height to diameter ratio is an exceptional parameter whose significance stems from the fact that it accommodates both the vertical and lateral dimensions of the dome, affecting the soil-disc contact area directly. Disc coverage ratio also showed a significant contribution (by $31.2 \%$ ) on normal adhesion force.
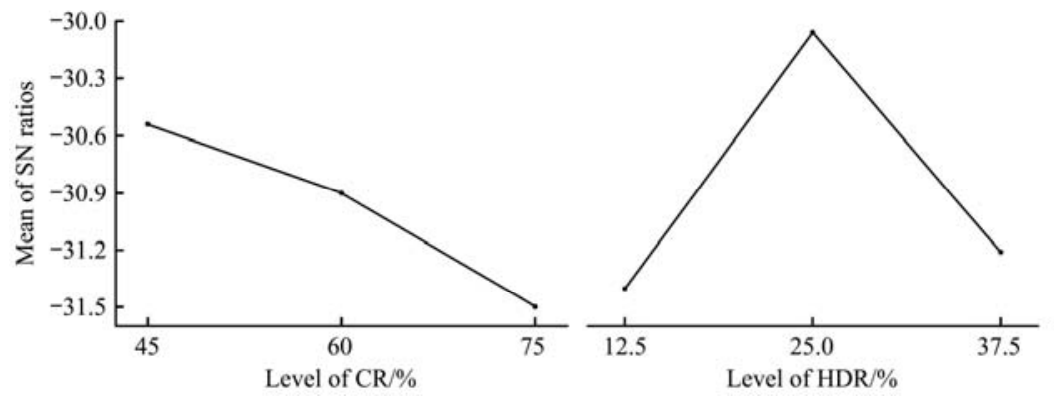

a. Normal adhesion force
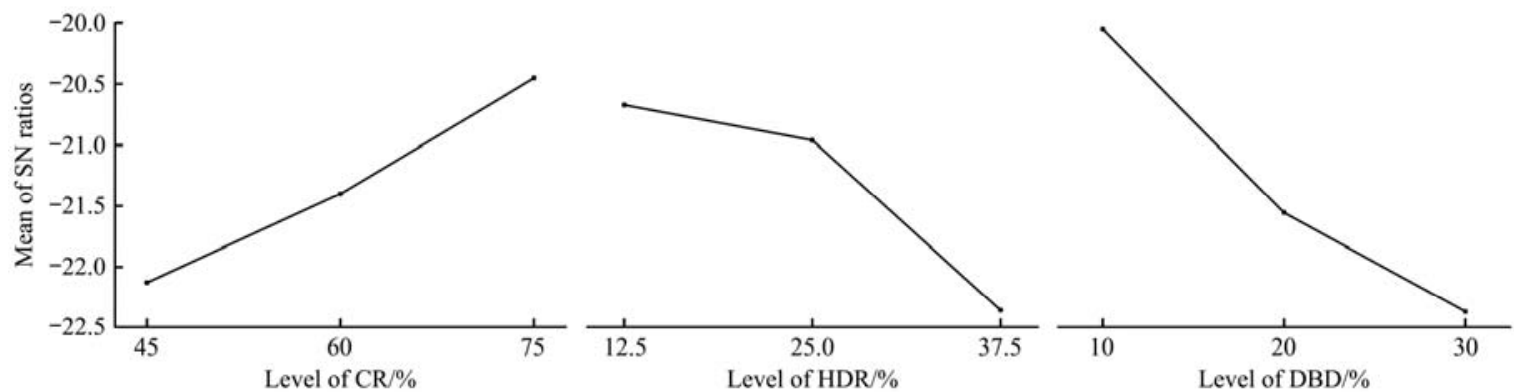

b. Disc sinkage

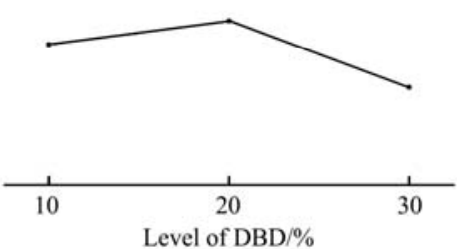

Figure 8 Effects of parameters levels on average $\mathrm{S} / \mathrm{N}$ ratio for normal adhesion force and disc sinkage 
Table 5 Results of ANOVA for normal adhesion force and disc sinkage

\begin{tabular}{|c|c|c|c|c|c|c|c|}
\hline & Variance source & DF & Sum of squares & Mean square & $F$-value & $p$-value & Contribution/\% \\
\hline \multirow{6}{*}{ Normal adhesion force $(\mathrm{Fa})$} & $\mathrm{CR}$ & 2 & 67.7 & 33.9 & 57.29 & $<0.001$ & 31.2 \\
\hline & HDR & 2 & 108.8 & 54.5 & 92.13 & $<0.001$ & 50.2 \\
\hline & DBD & 2 & 9.0 & 4.4 & 7.52 & 0.008 & 4.1 \\
\hline & CR*HDR & 4 & 8.8 & 2.2 & 3.69 & 0.035 & 4.1 \\
\hline & $\mathrm{CR}^{*} \mathrm{DBD}$ & 4 & 15.5 & 3.9 & 6.57 & 0.005 & 7.2 \\
\hline & Total & 26 & 216.8 & & & & 100 \\
\hline \multirow{7}{*}{ Test disc sinkage $(U)$} & $\mathrm{CR}$ & & 22.4 & 11.19 & 32.38 & $<0.001$ & 22.4 \\
\hline & HDR & & 27.7 & 13.86 & 40.11 & $<0.001$ & 27.8 \\
\hline & DBD & & 42.3 & 21.2 & 61.28 & 0.008 & 42.5 \\
\hline & HDR*DBD & & 1.8 & 0.42 & 1.21 & 0.345 & 1.7 \\
\hline & $\mathrm{CR} * \mathrm{DBD}\} e^{\Delta}$ & $4\} 16$ & $1.1\} 5.5$ & 0.35 & & & 5.6 \\
\hline & Error & 8 & 3.2 & & & & \\
\hline & Total & & 99.7 & & & & 100 \\
\hline
\end{tabular}

The percentage contributions of the disc coverage ratio, dome height to diameter ratio, and dome base diameter on the sinkage of discs were found to be $22.4 \%, 27.8 \%$, and $42.5 \%$, respectively. Thus, the diameter of the dome base had the greatest impact on disc sinkage. To obtain reliable results, error contribution values must be less than $20 \%{ }^{[27]}$. Thereby, the error contributions for normal adhesion force (3.2\%) and disc sinkage (5.6\%) were both within the acceptable range. Since the mean square of HDR*DBD was less than the mean square of error in the variance analysis of normal adhesion force, HDR*DBD was included in the error term, and the corrected error $e^{\Delta}$ was obtained.

\subsection{Evaluation of experimental results}

The relationships between control parameters and measured values of normal adhesion force and sinkage of domed discs were displayed graphically using the contour plot in two dimensions in Figure 9. As observed, at the same dome base diameter, as the coverage ratio increased, test disc sinkage decreased owing to the increased total volume of domes. This can be explained by Archimedes' principle, where the upward reaction force that is exerted on the disc is directly proportional to the weight of the soil particles that the disc displaces.

At all levels of disc height to diameter ratio, the normal adhesion force increased as the disc coverage ratio increased, possibly because the contact area at the soil-disc interface increased. At all levels of dome coverage ratio and dome base diameter, it was seen that at low dome surface area $(\mathrm{HDR}=12.5 \%)$, the normal adhesion force was comparatively high, most probably because of the low convexity of domes, thereby its inability to break the continuity of interfacial water film. As the dome's convexity increased to $\mathrm{HDR}=25 \%$, the normal adhesion force decreased; this reduction of soil-disc adhesion may be attributed to the impact of the gas layer formed on the surface of the concave areas between adjacent domes ${ }^{[28]}$. With increased dome surface area even further $(\mathrm{HDR}>25 \%)$, the soil-disc adhesion increased once more, most likely due to increased total volume of domes, which increased the attached area of the water film. These results are consistent with that of Benard et al. ${ }^{[21]}$, who found that a dome with an $\mathrm{HDR}<25 \%$ resulted in a significant reduction in normal adhesion force in sticky soil.
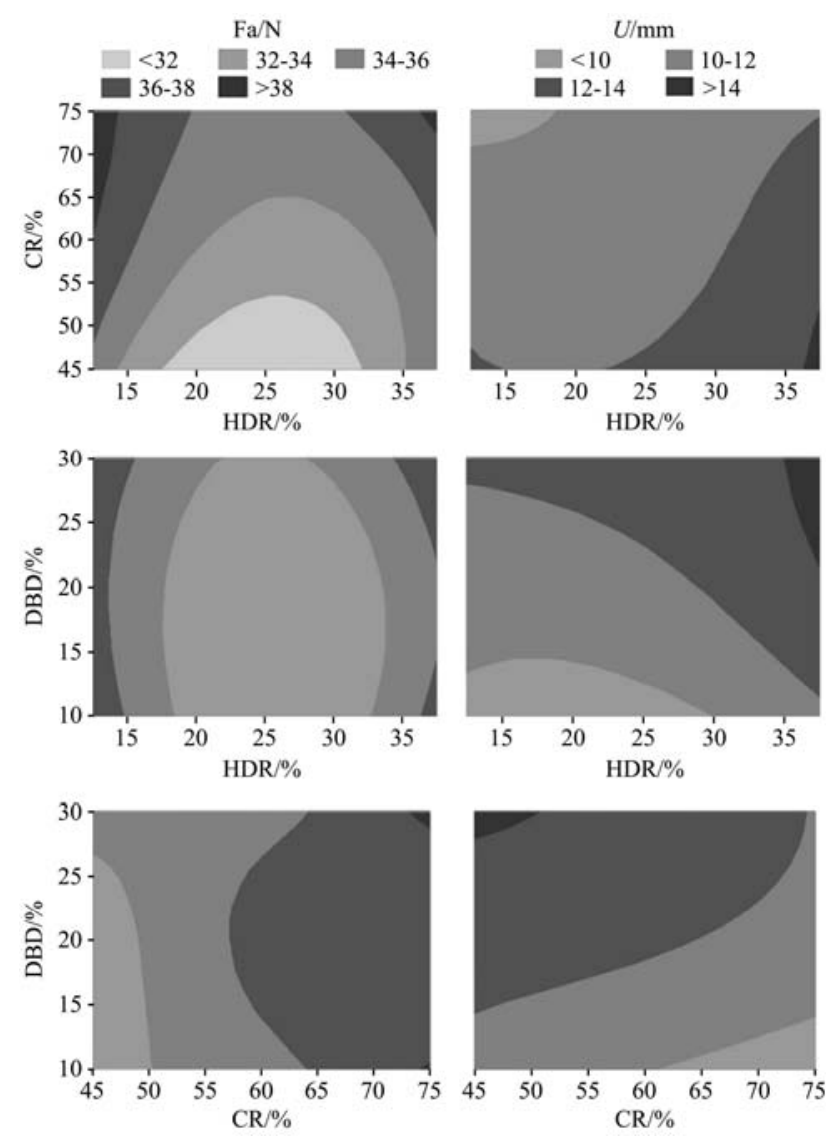

a. normal adhesion force

b. Disc sinkage

Figure 9 Influences of parameters levels on normal adhesion force and disc sinkage

3.4 Effect of certain soil conditions on normal adhesion force

Figure 10 shows the average values of normal adhesion force of flat disc (control) versus optimized domed disc (Disc No. 13) in two different soil textures: silty loam (S1) and sandy clay loam (S2) at three different moisture content levels: $23 \%, 30 \%$, and $37 \%$.

In all treatments, the optimized domed disc provided a lower normal adhesion force than the flat disc (about $7 \%$ to $18 \%$, depending on soil condition), which is consistent with previous research on the impact of surface shape modifications on soil-tool adhesion $^{[14,29]}$. This reduction may be attributed to air retention in the concave areas between adjacent domes, which creates a gas 
isolation layer that reduces soil-disc adhesion ${ }^{[28]}$. A summary of the statistical analysis is provided in Table 6. According to the paired samples $T$-test, the normal adhesion force between the flat disc and the optimized domed disc was significantly different $(p<0.05)$ in all treatments.

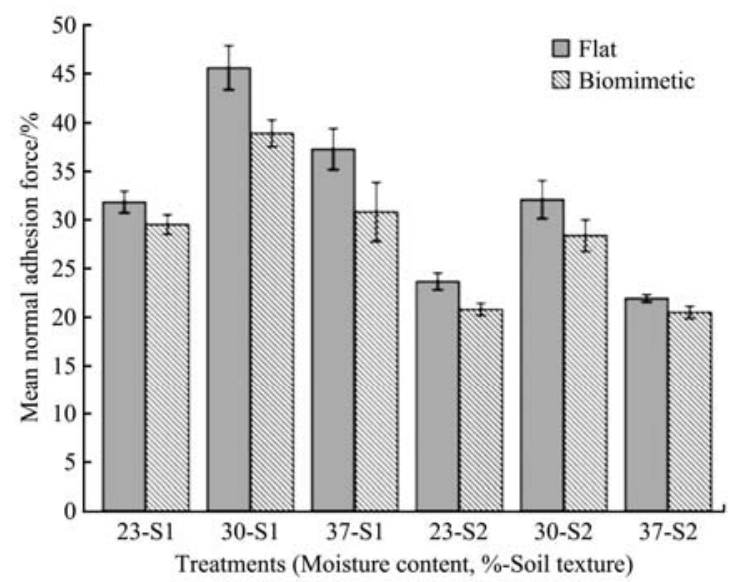

Figure 10 Mean normal adhesion force comparison between flat and biomimetic disc in all treatments

Table 6 Statistical analysis on normal adhesion force of flat disc against optimized biomimetic disc

\begin{tabular}{lccccc}
\hline \multirow{2}{*}{ Test condition } & Disc type & Mean Fa/N & Std. dev & $p$ value & IMPV/\% \\
\hline \multirow{2}{*}{$23 \%$ MC, S1 } & Flat & 31.8 & 0.45 & 0.001 & 7.23 \\
& Biomimetic & 29.5 & 0.40 & & \\
\hline \multirow{2}{*}{$30 \%$ MC, S1 } & Flat & 45.6 & 0.92 & 0.006 & 14.70 \\
& Biomimetic & 38.9 & 0.55 & & \\
\hline \multirow{2}{*}{$37 \%$ MC, S1 } & Flat & 37.3 & 0.85 & 0.011 & 17.40 \\
& Biomimetic & 30.8 & 1.20 & & \\
\hline \multirow{2}{*}{$23 \%$ MC, S2 } & Flat & 23.7 & 0.35 & 0.014 & 12.20 \\
& Biomimetic & 20.8 & 0.25 & & \\
\hline \multirow{2}{*}{$30 \%$ MC, S2 } & Flat & 32.1 & 0.79 & 0.044 & 11.50 \\
& Biomimetic & 28.7 & 1.20 & & \\
\hline \multirow{2}{*}{$37 \%$ MC, S2 } & Flat & 22.0 & 0.15 & 0.002 & 6.80 \\
& Biomimetic & 20.5 & 0.25 & & \\
\hline
\end{tabular}

Srivastava et al. ${ }^{[9]}$ stated that soil-tool adhesion is caused by the surface tension and viscosity of the interfacial water film, which is dependent on soil moisture content. As shown in Figure 10 , the measured normal adhesion force is relatively low around the plastic limit of soil. The normal adhesion force increased as the soil moisture content increased within the plastic range; but, as the soil moisture content approached the liquid limit of soil, the normal adhesion force decreased again. These results are similar to the results obtained by Tong et al. ${ }^{[16]}$ The soil fine particles content (clay and fine silt) has a significant effect on soil adhesive characteristics by virtue of the large surface area and chemical bonds of clay minerals ${ }^{[30]}$, which may explain the relatively high normal adhesion force of silty loam soil (S1), compared to sandy clay loam soil (S2). Hence, it can be inferred that the soil moisture content and soil texture are essential parameters that influence the normal adhesion force.

\section{Conclusions}

In this study, Taguchi orthogonal array L27 $\left(3^{3}\right)$ was used to determine the optimum dimensions of the domed surface that minimize normal adhesion force and disc sinkage simultaneously.

1) According to the analysis of variance (ANOVA), the dominant factor affecting the normal adhesion force of domed discs was the dome height to diameter ratio, which contributed $50.2 \%$, while the dominant factor influencing disc sinkage was dome base diameter which contributed $42.5 \%$.

2) It was observed that disc number 13, i.e., disc coverage ratio of $60 \%$, dome height to diameter ratio of $25 \%$ and dome base diameter of $10 \mathrm{~mm}$, was the most appropriate for the well-balanced improvement of normal adhesion force $(31.4 \mathrm{~N})$ and sinkage (9.08 mm) simultaneously.

3) The optimized domed disc provided a lower normal adhesion force than the flat disc in all treatments (about $7 \%$ to $18 \%$, depending on soil condition)

The results of this research can be used to promote both the manufacturing of soil-touching parts and academic research.

\section{[References]}

[1] Hamzei J, Seyyedi M. Energy use and input-output costs for sunflower production in sole and intercropping with soybean under different tillage systems. Soil and Tillage Research, 2016; 157: 73-82.

[2] Singh G, Singh D. Optimum energy model for tillage. Soil and Tillage Research, 1986; 6(3): 235-245.

[3] Eriksson R, Schatz T. Rheological properties of clay material at the solid/solution interface formed under quasi-free swelling conditions. Applied Clay Science, 2015; 108: 12-18.

[4] Pan J Z. The general rheological model of paddy soils in South China. Journal of Terramechanics, 1986; 23(2): 59-68.

[5] Maciel G D, Santos H K, Ferreira F D. Rheological analysis of water clay compositions in order to investigate mudflows developing in canals. Journal of the Brazilian Society of Mechanical Sciences and Engineering, 2009; 31(1): 64-74.

[6] Feng W X, Wu D L, Ma J S, He J. Present situation and problems of soil pressure-sinkage model fitting method. In IOP Conference Series: Earth and Environmental Science, 2018; 189(2): 022010. doi: 10.1088/1755-1315/189/2/022010.

[7] Salokhe V M, Gee-Clough D, Manzoor S, Singh K K. Improvement of the tractive performance of cage wheel lugs by enamel coating. Journal of Agricultural Engineering Research, 1990; 45: 209-224.

[8] Li B, Chen Y, Chen J. Modeling of soil-claw interaction using the discrete element method (DEM). Soil and Tillage Research, 2016; 158: 177-185.

[9] Srivastava A K, Goering C E, Rohrbach R P, Buckmaster D R. Soil tillage. in: Engineering Principles of Agricultural Machines, 2nd Ed, ASABE, 2006; pp.169-230. doi: 10.13031/2013.41470.

[10] Soni P, Salokhe V M. Theoretical analysis of microscopic forces at soil-tool interfaces: a review. Agricultural Engineering International: the CIGR Journal, 2006; 3: 101-115.

[11] Goshtasb A K, Fielke J, Desbiolles J. A review of soil/tool adhesion principles and approaches to reducing limitations of disc seeders. Proceedings of the 2009 CIGR International Symposium of the Australian Society for Engineering in Agriculture, 2009; pp.208-215.

[12] Qian D H, Zhang J X. Research on adhesion and friction of soil against metallic materials. Acta Agromechanica, 1984; 15(1): 70-78.

[13] Desbiolles J. Disc seeders: An overview of benefits and limitations experienced in the paddock. WANTFA New Frontiers Newsletter, 2008; 16(3): 77-80.

[14] Ren L Q, Chen D X, Chen B C. A summary of study on soil adhesion. Transactions of the CSAE, 1990; 6(1): 1-7. (in Chinese)

[15] Soni P, Salokhe V M, Nakashima H. Modification of a mouldboard plough surface using arrays of polyethylene protuberances. Journal of Terramechanics, 2007; 44(6): 411-422.

[16] Tong J, Moayad B Z, Ma Y H, Sun J Y, Chen D H, Jia H L, et al. Effects of biomimetic surface designs on furrow opener performance. Journal of Bionic Engineering, 2009; 6(3): 280-289.

[17] Marani S M, Shahgholi G, Moinfar A. Effect of nano coating materials on reduction of soil adhesion and external friction. Soil and Tillage Research, 2019; 193: 42-49.

[18] Wang X L, Ito N, Kito K, Garcia P P. Study on use of vibration to reduce soil adhesion. Journal of Terramechanics, 1998; 35(2): 87-101. 
[19] Ren L Q, Cong Q, Tong J, Chen B C. Reducing adhesion of soil against loading shovel using bionic electro-osmosis method. Journal of Terramechanics, 2001; 38(4): 211-219.

[20] Ren L Q, Han Z W, Li J Q, Tong J. Experimental investigation of bionic rough curved soil cutting blade surface to reduce soil adhesion and friction. Soil and Tillage Research, 2006; 85(1-2): 1-12.

[21] Benard C H, Emmanuel S T. Effects of bionic non-smooth surface on reducing soil resistance to disc ploughing. Science China: Technological Sciences, 2010; 11: 2960-2965.

[22] Soni P, Salokhe V M. Influence of dimensions of UHMW-PE protuberances on sliding resistance and normal adhesion of Bangkok clay soil to biomimetic plates. Journal of Bionic Engineering, 2006; 3(2): 63-71.

[23] Wang Y, Xue W, Ma Y, Tong J, Liu X, Sun J. DEM and soil bin study on a biomimetic disc furrow opener. Computers and Electronics in Agriculture, 2019; 156: 209-216.

[24] Seleiman M F, Kheir A, Al-Dhumri S, Alghamdi A G, Omar E S, Aboelsoud $\mathrm{H} \mathrm{M}$, et al. Exploring optimal tillage improved soil characteristics and productivity of wheat irrigated with different water qualities. Agronomy, 2019; 9(5): 233. doi: 10.3390/agronomy9050233.

[25] Debnath S, Reddy M M, Yi Q S. Influence of cutting fluid conditions and cutting parameters on surface roughness and tool wear in turning process using Taguchi method. Measurement, 2016; 78: 111-119.

[26] Kivak T. Optimization of surface roughness and flank wear using the Taguchi method in milling of Hadfield steel with PVD and CVD coated inserts. Measurement, 2014; 50: 19-28.

[27] Manivel D, Gandhinathan R. Optimization of surface roughness and tool wear in hard turning of austempered ductile iron (grade 3) using Taguchi method. Measurement, 2016; 93: 108-116.

[28] Cong Q, Ren L Q, Chen B C, Yan B Z. Using characteristics of burrowing animals to reduce soil-tool adhesion. Transactions of the ASAE, 1999; 42(6): 1549-1556.

[29] Zhou H, Shan H, Tong X, Zhang Z, Ren L. The adhesion of bionic non-smooth characteristics on sample surfaces against parts. Materials Science and Engineering: A, 2006; 417(1-2): 190-196.

[30] Das B, Sobhan K, Das B. A Historical Perspective. In: Principles of Geotechnical Engineering 5th Ed. Instructor, 2016; pp.7-35. 